\title{
Association of Citrus Virus A to Citrus Impietratura Disease Symptoms
}

\author{
Despoina Beris, ${ }^{1}$ Malandraki Ioanna, ${ }^{1}$ Nikon Vassilakos, ${ }^{1}$ Ioannis Theologidis, ${ }^{1}$ Aggeliki Rampou, ${ }^{1}$ Oxana Kektsidou, ${ }^{1}$ \\ Sebastien Massart, ${ }^{2}$ and Christina Varveri ${ }^{1, \dagger}$ \\ ${ }^{1}$ Laboratory of Virology, Scientific Directorate of Phytopathology, Benaki Phytopathological Institute, Athens 14561, Greece \\ ${ }^{2}$ Laboratory of Plant Pathology, TERRA, Gembloux Agro-Bio Tech, University of Liège, Gembloux 5030, Belgium \\ Accepted for publication 8 March 2021.
}

\begin{abstract}
Citrus impietratura disease (CID) is a graft transmissible, virus-like disease observed in old-line citrus trees; its characteristic symptom is the appearance of gum in the albedo of the affected fruits. To identify the causal agent of the disease, high-throughput sequencing (HTS) was performed on symptomatic orange fruits. The analysis of the obtained data revealed in all samples mixed infections of viroids commonly found in citrus trees together with the recently described citrus virus A (CiVA). Examination of additional symptomatic fruits with conventional reverse transcription PCR led to the identification of a single CiVA infection in one tree, which was verified by HTS. Indexing of the single CiVA-infected tree on indicator plants resulted in the appearance of characteristic symptoms in the leaves that were correlated with virus
\end{abstract}

ABSTRACT

Citrus impietratura disease (CID) is considered a graft-transmissible disease of virus-like etiology. Impietratura was originally described in 1930 in Palestine and later, in 1955, in Italy (reviewed in Roistacher 2004). CID affects mainly old-line orange (Citrus sinensis) and grapefruit (Citrus paradisi) trees, and disease symptoms appear predominantly in fruits during color break as dark green, flat or raised areas. These areas contain pockets of gum in the albedo tissue, and as the gum desiccates during later maturation stages, they become brown, and the fruit hardens and usually remains smaller in size. Notably, CID symptoms are not uniformly developed, and it is common that they can be observed only in particular branches of a certain tree. Severe fruit drop may occur in affected trees over the years in combination with environmental conditions such as temperature (reviewed in Roistacher 2004; Timmer et al. 2000).

Although CID is considered a widespread disease in citrus-growing regions worldwide and mainly in the Mediterranean basin, the responsible infectious agent remains unknown. Furthermore, according to the latest European legislation (Commission Implementing Regulation [EU] 2019/2072), the CID agent is enlisted among the regulated non-quarantine pests and should be absent from certified Citrus spp. propagation material. So far, the detection of CID agents, as proposed by the European and Mediterranean Plant Protection Organization, is

${ }^{\dagger}$ Corresponding author: C. Varveri; c.varveri@bpi.gr

Funding: This work was supported by the Research Infrastructure "Upgrading the Plant Capital (PlantUp)" (MIS 5002803), which is implemented under the action "Reinforcement of the Research and Innovation Infrastructure," funded by the operational program "Competitiveness, Entrepreneurship and Innovation" (NSRF 20142020) and co-financed by Greece and the European Union (European Regional Development Fund). This work was also funded by the European Cooperation in Science and Technology (COST) action FA1407.

*The $e$-Xtra logo stands for "electronic extra" and indicates there are supplementary tables and one supplementary figure published online.

The author(s) declare no conflict of interest.

(C) 2021 The American Phytopathological Society accumulation. Moreover, a comparative analysis among symptomatic and asymptomatic fruits derived from the same trees was performed and included the single CiVA-infected orange tree. The analysis revealed a positive correlation between the appearance of symptoms and the accumulation of CiVA RNAs. To facilitate CiVA detection during certification programs of propagation material, a quantitative RT-PCR targeting the movement protein of the virus was developed and evaluated for reliable and sensitive detection of the virus. To the best of our knowledge this is the first study that associates CiVA with the appearance of CID symptoms.

Keywords: disease etiology, real-time PCR, virus characterization based on indexing of indicator plants (PM 4/12), a task that is laborious and requires $\leq 2$ years until completion. The identification and characterization of the virus-like CID agent is a prerequisite for the development of detection molecular methods, which would facilitate the implementation of certification programs for propagation material of citrus varieties and rootstocks.

The development of high-throughput sequencing (HTS) over the last decade has enriched our knowledge of plant viruses, and it is now used for a wide range of scientific purposes, such as detection of known viruses and the discovery of new viruses in order to further associate them with diseases of unknown etiology, population genetic studies, mapping of viromes in economically important agricultural regions and crops, host-virus interactions, and certification of plant propagation material (reviewed in Villamor et al. 2019).

In citrus trees, HTS has led to the discovery of members of the recently accepted Coguvirus genus belonging to the Bunyavirales order. Coguviruses have a segmented genome composed of two single-stranded RNAs encoding only three proteins: the RNA-dependent-RNA-polymerase (RdRp), the nucleocapsid (NP), and the movement protein (MP). In all genus members, RdRp is encoded by the large (L) negative strand RNA, and NP and MP are encoded by an ambisense medium (M) RNA. So far, with the use of HTS technologies six other members are enlisted in the genus. These viruses were found in Citrus spp. (Navarro et al. 2018a, b), apple (Rott et al. 2018; Wright et al. 2018), pear (Svanella-Dumas et al. 2019), and grapevine (Diaz-Lara et al. 2019). In citrus trees, two coguviruses with a bipartite RNA genome have been reported. The first one, citrus concave gum-associated virus (CCGaV), is associated with concave gum disease (Navarro et al. 2018a), whereas citrus virus A (CiVA) was described in a nonsymptomatic, field-grown sweet orange tree in southern Italy (Navarro et al. 2018b).

The association of a novel virus with specific symptoms through the fulfillment of Koch's postulates and its impact in agronomy through their in-depth biological characterization can be challenging and time consuming, especially in trees. This challenge can be attributed to the occurrence of mixed infections with other viruses or viroids, low virus concentration, differential virus distribution in 
distinct plant parts, and the impact of the environmental conditions and the genetic background of the host. In accordance with this argument, despite the appearance of an increasing number of publications reporting the presence of novel viruses in distinct tree hosts, in only few of them is their association with disease symptoms supported (Hou et al. 2020; Massart et al. 2017). To overcome these constraints, a new systematic approach for the association of an identified virus with a disease has been proposed, based on experimental evidence and epidemiological data strengthened by statistical analysis (Fox 2020).

In this study, HTS was used for identification of the CID infectious agent along with a comparative analysis between trees that never showed CID symptoms over time and trees producing both symptomatic and asymptomatic orange fruits. Our results suggest that the appearance of CID symptoms is related to the recently described CiVA. More importantly, the analysis of symptomatic and asymptomatic orange fruits derived from the same trees along with the analysis of symptomatic and asymptomatic leaves originating from the same branch of indicator plants revealed a strong correlation between symptom development and quantity of CiVA RNAs. Taking into account the uneven presence of the virus within plants, a quantitative reverse transcription (RT)-PCR protocol was developed based on the movement protein genomic region for sensitive and reliable detection of the virus.

\section{MATERIALS AND METHODS}

Plant material. Twenty-four $C$. sinensis cultivar Valencia trees, 20 to 30 years old, and two Citrus paradisi trees of the same age exhibiting typical CID symptoms were selected from an orchard (Argolida, Peloponnese, Greece) that has been monitored for the disease for at least 10 years. Five trees from the same orchard without a record of CID symptoms were considered CID-free samples. Samples were collected for the last 3 years (2018 to 2020) in late winter and spring. In trees showing CID, branches could be distinguished between those carrying symptomatic fruits and those bearing fruits without symptoms; therefore, a further classification of symptomatic and asymptomatic fruits derived from the same CID tree was made. In addition, 81 samples from nurseries around Greece, which included several citrus species (sweet orange, mandarin, lemon, sour orange, grapefruit, lime, rough lemon, and bergamot) were tested for CiVA presence during the development of the detection method.

Indexing was performed on virus-tested negative rough lemon indicator plants maintained in an environmentally controlled insect-proof greenhouse.

High-throughput sequencing. Total RNA was purified from tissues originating from the albedo and calix regions close to the gum pockets with the RNeasy Plant Mini Kit (QIAGEN, Hilden, Germany) according to the manufacturer's instructions. Depletion of ribosomal RNA was performed with the Ribo-Zero rRNA Removal Kit (Plant Leaf, Illumina, San Diego, CA) before library preparation. The library preparation followed the TruSeq Stranded Total RNA Library Prep Kit (Illumina). The samples were sequenced at the GIGA facilities of Liège University (Liege, Belgium) on the Illumina Nextseq 500 platform (Illumina, San Diego, CA) and in the Greek Genome Center (Biomedical Research Foundation Academy of Athens, BRFAA, Greece) on a NovaSeq 6000 or a NextSeq 500 sequencing platform (Illumina, San Diego, CA).

Real-time PCR and quantitative PCR assays. For total RNA extraction, $0.5 \mathrm{~g}$ of tissue was collected from fruits, leaves, or bark scrapings and was homogenized in $5 \mathrm{ml}$ of SE buffer (Thompson et al. 2003). Subsequently, RNA was extracted from $200 \mu$ of the homogenate with Nucleozol reagent (Macherey-Nagel) according to the manufacturer's instructions. Synthesis of complementary DNA (cDNA) was performed from $500 \mathrm{ng}$ to $1 \mu \mathrm{g}$ of total RNA with Superscript II RTase (Thermo Scientific) with $0.6 \mu \mathrm{M}$ of OligoDT primer mix and $1.2 \mu \mathrm{M}$ of random hexamer primers (Takara) according to the manufacturer's instructions.

For CiVA detection and identification, both conventional and quantitative PCRs were developed based on the HTS data and the National Center for Biotechnology Information submitted sequences of CiVA, which targeted each of the virus putative RdRp, NP, and MP genes. All primers are described in Supplementary Table S1.

Conventional PCR was applied on $1 \mu \mathrm{l}$ of synthesized cDNA with Kapa Taq Polymerase reagents (Kapa Biosystems). Reaction mixture consisted of $1 \times$ Kapa Taq Buffer A containing $1.5 \mathrm{mM}$ of $\mathrm{MgCl}_{2}, 0.3$ $\mathrm{mM}$ of deoxynucleoside triphosphate mixture, $0.3 \mu \mathrm{M}$ of each primer, and 1.25 units of Kapa Taq Polymerase. PCRs were initially denaturated at $95^{\circ} \mathrm{C}$ for $3 \mathrm{~min}$ followed by 40 cycles of amplification at $95^{\circ} \mathrm{C}$ for $30 \mathrm{~s}, 50^{\circ} \mathrm{C}$ for $30 \mathrm{~s}$, and $72^{\circ} \mathrm{C}$ for $45 \mathrm{~s}$ and $5 \mathrm{~min}$ of final extension at $72^{\circ} \mathrm{C}$. PCR products were visualized after electrophoresis in a $1 \%$ agarose gel.

cDNA synthesis for SYBR Green-based quantitative PCR (qPCR) was performed as for conventional PCRs with the difference that first, a deoxyribonuclease treatment (DNAse I, New England Biolabs) was performed according to the manufacturer's instructions to avoid contamination with genomic DNA. The cDNA was diluted five times, and $1 \mu \mathrm{l}$ was used as template in a $10-\mu \mathrm{l}$ reaction with a KAPA SYBR FAST qPCR Master Mix (Kapa Biosystems) kit in a StepOnePlus Real-Time PCR System (Applied Biosystems, Thermo Fisher Scientific) apparatus. Reaction mixture contained $1 \times$ KAPA SYBR FAST qPCR Master Mix, 1× ROX (High) passive reference dye, and $0.2 \mu \mathrm{M}$ of each primer. The RT-qPCR conditions consisted of an initial denaturation step at $95^{\circ} \mathrm{C}$ for $3 \mathrm{~min}$ and 40 cycles of amplification at $95^{\circ} \mathrm{C}$ for $3 \mathrm{~s}$ and $60^{\circ} \mathrm{C}$ for $30 \mathrm{~s}$. A dissociation curve followed the amplification cycles, with an initial denaturation step at $95^{\circ} \mathrm{C}$ for $30 \mathrm{~s}$, followed by $60^{\circ} \mathrm{C}$ for $1 \mathrm{~min}$ and continuous heating at $0.3^{\circ} \mathrm{C} / \mathrm{s}$ to $95^{\circ} \mathrm{C}$.

In addition, cDNAs from selected samples were tested for the presence of five common citrus viruses (citrus variegation virus [CVV], citrus psorosis virus $[\mathrm{CPsV}], \mathrm{CCGaV}$, citrus tatter leaf virus [CTLV], and citrus leaf blotch virus [CLBV]) and six viroids (citrus bent leaf viroid [CBLVd], citrus viroid $\mathrm{V}[\mathrm{CVdV}]$, citrus bark cracking viroid [CBCVd], citrus dwarfing viroid [CDVd], hop stunt viroid [HSVd], and citrus exocortis viroid [CEVd]). Primers, annealing temperatures, and amplification time are provided in Supplementary Table S2. Citrus tristeza virus (CTV) testing was performed by double antibody sandwich enzyme-linked immunosorbent assay (LOEWE, Germany) according to manufacturer's instructions.

Bioinformatic and statistical analysis. All data obtained from the HTS analyses were analyzed in Geneious Prime (version R11; Biomatters, New Zealand). Initially, raw reads (of 75 to $150 \mathrm{bp}$ length) without adapter sequences were trimmed and filtered with the BBDuck algorithm. Removal of duplicate reads was performed with standard algorithms included in Geneious Prime. In case of paired reads, the resulting unique reads were paired and merged. Subtraction of the reads belonging to the $C$. sinensis genome was performed with the Bowtie algorithm. The remaining nonhost reads were finally de novo assembled into contigs with the Geneious assembler. The latter were annotated with BLAST for the identification of viruses and viroids. Viral sequences obtained were confirmed by Sanger sequencing.

Variant calling was done with freebayes (version 1.3.2) and the already assembled and annotated CiVA genome used as a reference (Garrison and Marth 2012). Variants with a quality score of $>20$ were selected.

Comparative analysis for CiVA accumulation among different samples with RT-qPCR was performed via the $\Delta \Delta \mathrm{Ct}$ method with the CsUPL7 gene as reference (Mafra et al. 2012). Statistical analysis and multirun calibrations among plates were performed according to Steibel et al. (2009) and Ruijter et al. (2015), respectively.

Development of the RT-qPCR assay for CiVA detection. The RT-qPCR with SYBR Green and targeting the MP gene as described 
previously was further evaluated as a tool for CiVA detection. Because the use of an endogenous gene was not required for the detection application of the method, the DNase step was omitted. More specifically, the specificity, sensitivity, efficiency, and linearity of the method were evaluated and compared with that of the respective conventional RT-PCR (primers for both methods are described in Supplementary Table S1).

RNA transcripts were synthesized in vitro and used as standards essentially as described previously (Malandraki et al. 2017); the PCR product containing both the qPCR and conventional RT-PCR target sequences was produced by RT-PCR with primers MP-qF and MP-R (Supplementary Table S1) and cloned into the pCRIITOPO TA vector (Thermo Fisher Scientific). The recombinant pCRII-TOPO:CiVAmp vector was linearized, and RNA transcripts were synthesized with the MEGAscript T7 Transcription Kit (Thermo Fisher Scientific), according to the manufacturer's instructions. The DNA template was removed from the in vitro transcription reaction with TURBO DNase (Thermo Fisher Scientific) as described in the manufacturer's instructions. Standards were quantified with a NanoPhotometer TM P-Class P330 (IMPLEN) spectrophotometer, and the number of standard copies per nanogram was calculated via the following equation: copies per nanogram $=\left(N_{\mathrm{A}} \times A\right) /(n \times \mathrm{mw})$, where $N_{\mathrm{A}}$ is the Avogadro constant $\left(6.02 \times 10^{23}\right.$ molecules per mole $), A$ is the amount of the standard in grams, $n$ is the length of the standard in nucleotides, and mw is the molecular weight per nucleotide (considering average molecular masses of $340 \mathrm{Da}$ for one nucleotide of single-stranded RNA).

cDNA synthesis, primer concentrations, and reaction conditions were as described previously. Assays were performed in duplicate and in at least two individual runs. All appropriate controls (i.e., negative amplification control, negative isolation control, and positive amplification control) were included, and ROX was used as passive reference dye.

Six tenfold serial dilutions of the standards ranging from $10^{8}$ to $10^{2}$ copies were prepared in RNAse-free type 1 Milli-Q $\mathrm{H}_{2} \mathrm{O}$ (Merck) and mixed with $100 \mathrm{ng} / \mu \mathrm{l}$ of total RNA extracted from a sweet orange leaf sample tested negative for CiVA presence. Five serial 10-fold dilutions of total RNA extracted from a naturally infected CiVA plant
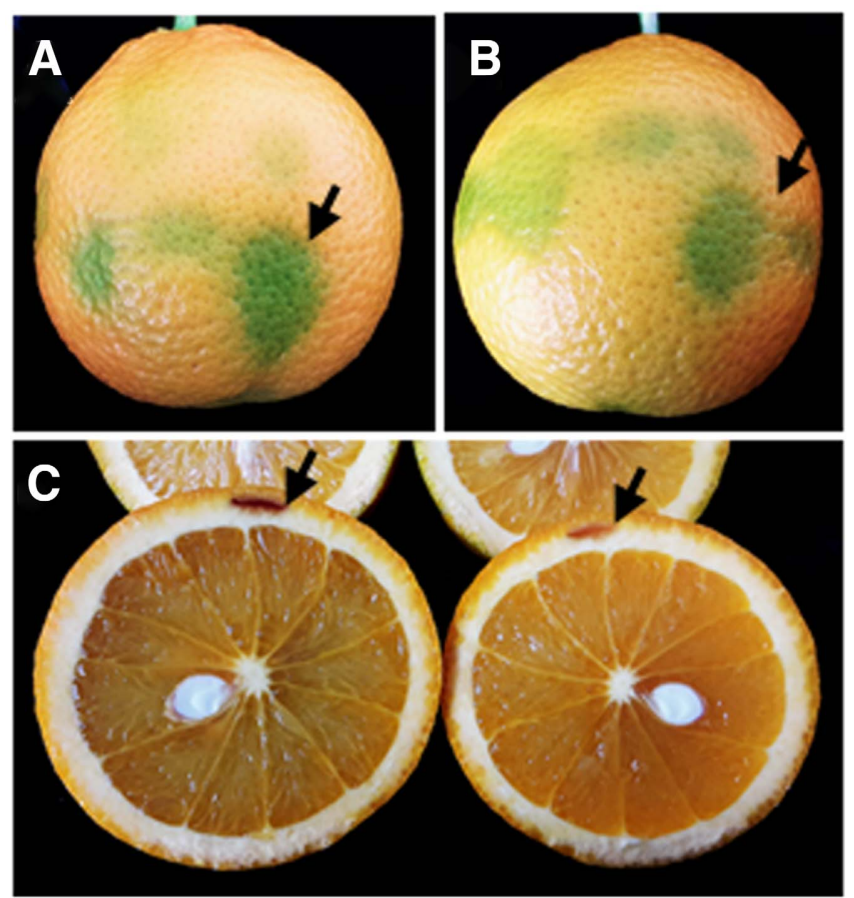

Fig. 1. Typical impietratura symptoms in Citrus sinensis cultivar Valencia fruits. A and B, Early symptoms of dark green areas on the surface of the affected fruits (indicated by arrows). C, Late symptoms of brown pockets of gum (arrows) in the albedo in sections of fruits. were also prepared in RNA derived from a virus-negative plant at a final concentration of $100 \mathrm{ng} / \mu \mathrm{l}$.

Specificity of the assay was tested with nontarget citrus viruses and viroids, namely $\mathrm{CPsV}, \mathrm{CTV}, \mathrm{CVV}$, HSVd, CEVd, CBCVd, and CDVd, as well as in several CiVA-free citrus species (sweet orange, Mexican lime, rough lemon, sweet tangor, and sour orange). Sensitivity, efficiency, and linearity of the qPCR assays were estimated by constructing standard curves. Evaluation of the method was carried out in 86 samples of several citrus species from nurseries and fields around Greece.

\section{RESULTS}

HTS reveals CiVA presence in all trees exhibiting CID symptoms. For the identification and characterization of the putative infectious agents responsible for CID, the virome of citrus trees exhibiting typical symptoms of the disease was examined (Fig. 1). Specifically, HTS was performed in the following samples: (A) a composite sample consisting of symptomatic fruits derived from several sweet orange and grapefruit trees aiming also to obtain information of the orchard viral load (Fig. 1); (B) separately, in a symptomatic (BS) and an asymptomatic (BAs) fruits derived from different branches of the same orange tree exhibiting CID; and (C) a symptomatic fruit from an orange tree tested negative for common citrus viruses and viroids via conventional methods (RT-PCR and ELISA).

HTS analysis in the RNA sequencing library from the first sample (A) (library F294) resulted in approximately $12 \mathrm{M}$ paired-end reads of 150 bp length. Analysis of the samples BS (library name A3) and BAs (library name A8) produced output of approximately $60 \mathrm{M}$ and $70 \mathrm{M}$ single-end reads of $75 \mathrm{bp}$ length, respectively. Finally, sample $\mathrm{C}$ analysis (library name A7) resulted in approximately $23 \mathrm{M}$ reads.

In all cases, the obtained data were analyzed with Geneious. The annotation of the contigs, derived from all four analyses with BLAST, revealed the presence of $\mathrm{CiVA}$ in all samples examined. In addition, in samples A, BS, and BAs, four viroids were detected: $\mathrm{CBCVd}$, CDVd, HSVd, and CEVd.

In samples A and B (in both BS and BAs specimens), two contigs with 6,687 and 2,734 bp length were annotated as the L and M RNA genomic segments of CiVA, respectively (Fig. 2). The assembled sequences obtained from the BS and BAs samples exhibited $100 \%$ identity at nucleotide level for both RNAs. The two L RNA consensus sequences obtained from each HTS analysis (isolates F294-Gr [A],
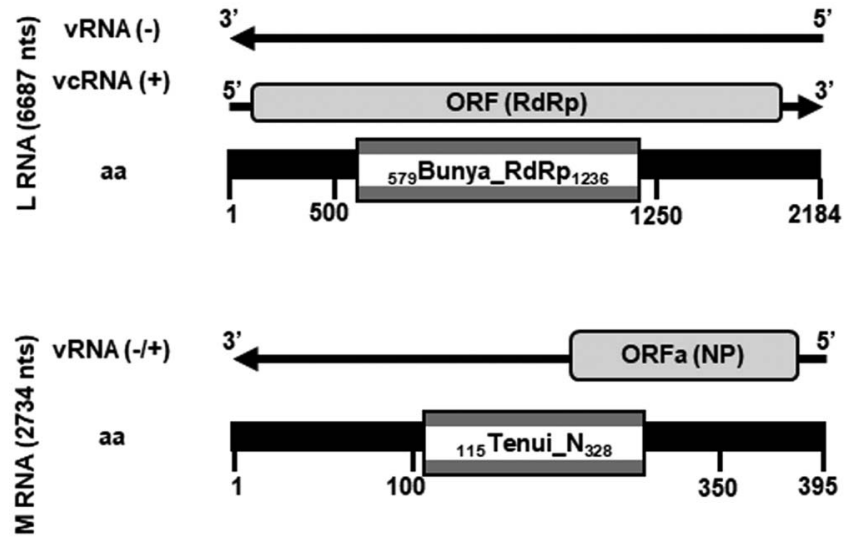

vcRNA (+l-)

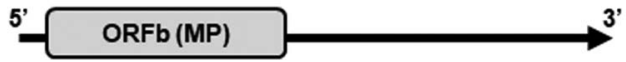

Fig. 2. Organization of citrus virus A genomic RNA segments as deduced by the analysis of high-throughput sequencing performed on impietratura symptomatic fruits. The negative, single-strand L RNA, 6,687 nucleotides (nts) in size, encodes the RNA-dependent RNA polymerase (RdRp) of the virus. The protein $(2,185$ amino acids [aa]) contains the conserved Bunya_RdRp viral domain. The ambisense, M RNA (2,734 nts) encodes the nucleocapsid protein (NP) with the characteristic Tenui_N motif and the movement protein (MP) of the virus. 
GenBank number MW148461, and A3-Gr [B], GenBank number MW148457), exhibited 96\% identity at nucleotide level with each other and 94\% with the CiVA isolate TX-NO from Texas (GenBank number MK689372).

In the same context, the two M RNA assembled sequences (isolate F294-Gr GenBank number MW148462 and isolate A3-Gr GenBank number MW148458) showed 98\% identity with each other and 94\% identity with the respective M RNA of TX-NO isolate (GenBank number MK689373). Conserved domain architecture retrieval tool analysis confirmed the presence of all conserved domains that are characteristic for the viruses of the Bunyavirales order (Bunya_RdRp and Tenui_N domains, Fig. 2).

In sample $\mathrm{C}$, the two CiVA RNA segments were produced by the de novo assembly of 3,841 reads for L RNA and 2,734 reads for M RNA. The obtained consensus sequences exhibited $99 \%$ identity at nucleotide level with the CiVA consensus sequences present in the BS tree.

Most importantly, the analysis of sample C after BLAST annotation of all contigs obtained, as well as of reads not used in the assembly (unused reads), confirmed the presence of only CiVA in the CID tree and the absence of any other virus or viroid. Conventional RT-PCRs targeting all putative CiVA genes, followed by Sanger sequencing, confirmed the HTS results and the presence of the two genomic RNAs of the virus in all HTS analyzed samples (Fig. 3).

Regarding the viroids identified in samples $\mathrm{A}$ and $\mathrm{B}$, each genome was derived from the annotation of a single contig. More specifically,
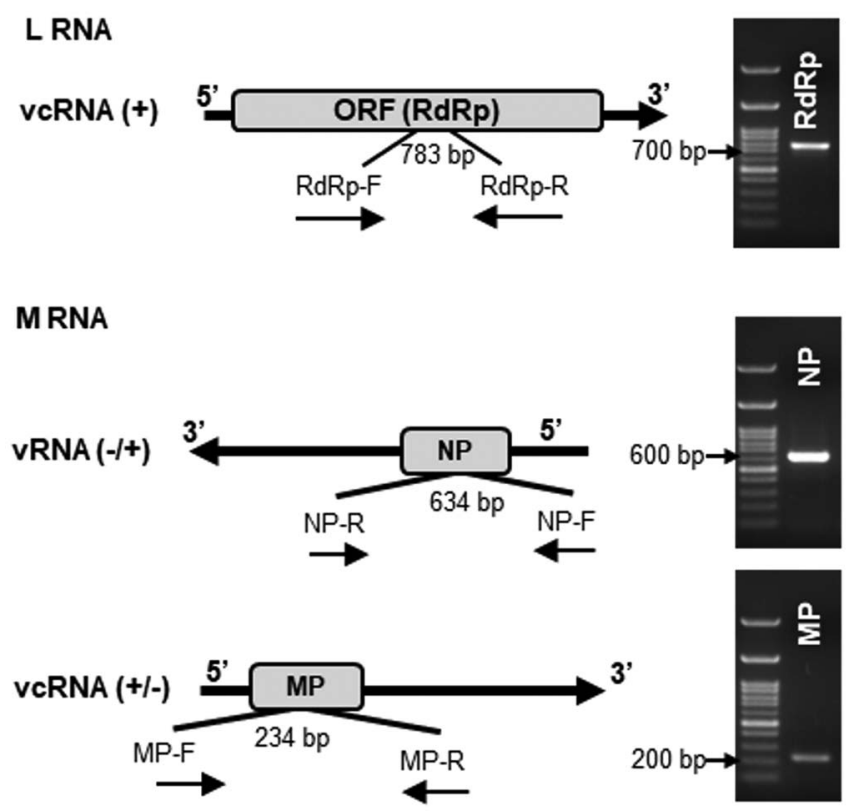

Fig. 3. Confirmation of the presence of the two citrus virus A segments deduced by high-throughput sequencing in impietratura symptomatic trees, with conventional reverse transcription PCR (RT-PCR). The RT-PCR assays targeted a 634-bp region of the RNA-dependent RNA polymerase (RdRp) open reading frame (ORF) of the L RNA, and in the M RNA a 634-bp and a 234-bp region of the nucleocapsid (NP) and movement (MP) protein ORFs, respectively.
BLAST results showed that $\mathrm{CBCVd}$ and CEVd consensus sequences exhibited 99\% identity with two Greek isolates (GenBank numbers JX259418 and JX259392, respectively) found in Poros Arboricultural Station, CDVd was identical with an isolate from Uruguay (GenBank number AY514448), and HSVd was identical with an isolate from the United States (GenBank number AF131251). Interestingly, the nucleotide comparison between the two consensus sequences obtained from each HTS and for each viroid showed $99 \%$ identity at the nucleotide level.

The presence of viroids identified by HTS was also confirmed by RT-PCR and Sanger sequencing of the obtained PCR products.

CiVA RNA accumulation is related to CID symptom development. CiVA was identified in all CID symptomatic samples analyzed by HTS, and in one case it was the only viral agent detected. To further investigate the association of CiVA with CID, 26 trees showing typical CID symptoms were examined for the presence of CiVA with a conventional RT-PCR that targeted the MP gene of the virus. Five asymptomatic trees that never exhibited symptoms and derived from the same orchard were included in the analysis as CID-free controls. The virus was ubiquitously detected in all symptomatic samples but was absent from the five nonsymptomatic ones.

The same samples were also tested for the presence of the four viroids (CBCVd, CDVd, HSVd, and CEVd) identified from the HTS analysis and of six viruses (CVV, CPsV, CCGaV, CTLV, CTV, and CLBV) and two more viroids commonly found in citrus species (CBLVd and CVdV). HSVd, CEVd, CBCVd, and CDVd were the most abundant viroids found in 25 of 26 symptomatic and in all asymptomatic trees, whereas three symptomatic trees were also found positive for CBLVd. Concerning the viruses tested, only $\mathrm{CPsV}$ was detected in six of the $26 \mathrm{CID}$ symptomatic trees (Table 1).

Subsequently, based on the observation that branches with symptomatic fruits coexisted with branches with asymptomatic fruits in the same CID tree, a possible relation of the presence of symptoms to CiVA titer was examined. Thus, 27 symptomatic and 22 asymptomatic fruits originating from nine CID trees of the Argolida orchard were collected and analyzed with RT-qPCR for the quantification of CiVA RdRp (L segment) and MP (M segment) RNA levels. The CiVA-only infected tree (sample $\mathrm{C}$ ) was also included in this analysis. As illustrated in Figure 4A, a statistically significant increase in the accumulation of the two viral RNAs was observed in the symptomatic fruits compared with asymptomatic ones. More specifically, a threefold and fourfold increase was recorded in the RdRp and MP expression levels, respectively, revealing differences in the quantity of the virus RNAs between symptomatic and asymptomatic tissues of the plant.

Identification of minor single-nucleotide variants in symptomatic and asymptomatic fruits. To get insight for possible qualitative differences between the virus populations in the symptomatic and asymptomatic fruits, the data obtained from the HTS analyses of the BS and BAs samples were analyzed for the identification of minor (their frequency in the assembly was close to 50\%) single nucleotide variants (SNVs) via a Bayesian approach. In total, seven SNVs were detected in the L RNA of the BS and the BAs sample. All SNVs were found in the RdRp encoding region. Two of them were common to the two samples, with one of them resulting in a nonsynonymous

TABLE 1. Examination of sweet orange and grapefruit trees from a Greek orchard for the presence of citrus virus A (CiVA) and common citrus infecting viruses and viroids

\begin{tabular}{|c|c|c|c|c|c|c|c|c|c|c|c|c|c|c|}
\hline \multirow{2}{*}{$\begin{array}{l}\text { Number of } \\
\text { trees tested }\end{array}$} & \multirow[b]{2}{*}{ Symptoms } & \multicolumn{7}{|c|}{ Viruses $^{\mathrm{a}}$} & \multicolumn{6}{|c|}{ Viroids $^{\mathrm{b}}$} \\
\hline & & CiVA & CTV & $\mathrm{CPsV}$ & $\mathrm{CVV}$ & CLBV & CTLV & $\mathrm{CCGaV}$ & HSVd & CEVd & CBLVd & $\mathrm{CBCVd}$ & $\mathrm{CDVd}$ & $\mathrm{CVdV}$ \\
\hline 26 & Symptomatic & $26 / 26$ & $0 / 26$ & $6 / 26$ & $0 / 26$ & $0 / 26$ & $0 / 26$ & $0 / 26$ & $25 / 26$ & $25 / 26$ & $3 / 26$ & $25 / 26$ & $25 / 26$ & $0 / 26$ \\
\hline 5 & Asymptomatic & $0 / 5$ & $0 / 5$ & $0 / 5$ & $0 / 5$ & $0 / 5$ & $0 / 5$ & $0 / 5$ & $5 / 5$ & $5 / 5$ & $0 / 5$ & $5 / 5$ & $5 / 5$ & $0 / 5$ \\
\hline
\end{tabular}

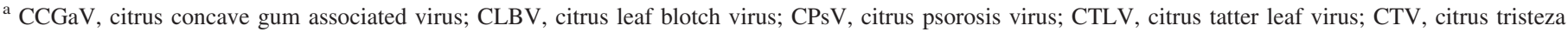
virus; $\mathrm{CVV}$, citrus variegation virus.

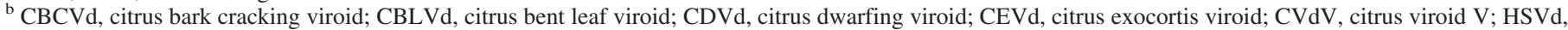
hop stunt viroid. 
substitution (Supplementary Fig. S1). Two more SNVs in each sample also resulted in nonsynonymous substitutions, whereas the three others did not alter the amino acid sequence of the protein (Supplementary Fig. S1). In the M RNA, SNVs of the BS sample were clustered in the MP open reading frame, and only one resulted in a nonsynonymous variant. Interestingly, all SNVs observed in the BAs sample were spanning the intergenic region between the two open reading frames, whereas only one synonymous variant was detected in the NP region (Supplementary Fig. S1). More importantly, the substitution $\mathrm{T}_{1468} \mathrm{G}$ identified in the one half of the reads mapped in this site is predicted to disrupt the transcription termination signal (TTS) of the respective variant (Supplementary Fig. S1).

Association of symptom development in rough lemon indicator plants with CiVA RNA accumulation. Buds excised from the single CiVA-infected tree were used for graft inoculation of virus-tested negative, rough lemon indicator plants. The plants were monitored for symptom development. Four months after grafting, all plants were tested for CiVA with RT-PCR and were found positive. Approximately 18 months after grafting, leaf flecking symptoms were observed in newly grown leaves in all indicator rough lemon plants (Fig. 4B). Virus concentration was quantified via RT-qPCRs targeting both RNAs in symptomatic and in asymptomatic leaves derived from the same indicator plant. In line with the results obtained from the expression analysis of the symptomatic and asymptomatic fruits, a large difference in CiVA RNA levels was recorded between symptomatic and asymptomatic leaves (Fig. 4C).

Development and evaluation of the new quantitative RT-qPCR: comparison with conventional RT-PCR assay. Three conventional RT-PCRs targeting each of the CiVA putative genes were designed in this study and tested for their suitability for
CiVA detection. First, all asymptomatic and symptomatic fruit samples derived from Argolida's orchard trees and described previously, as well as samples from asymptomatic trees from various nurseries and orchards in Greece, were tested by the three assays (Tables 2 and 3). Initially, the symptomatic and asymptomatic fruits were assessed. In all (27) symptomatic fruits tested, all three CiVA targets were ubiquitously amplified (Table 2). However, among asymptomatic samples (either fruits from CiVA-infected plants [Table 2] or citrus plants from nurseries and fields [Table 3]), the RdRp and MP of the virus were detected in only 33 of 108 samples, and NP was detected in only 18 out of 108 samples (Tables 2 and 3). To investigate the reason for this discrepancy, all asymptomatic samples in which RdRp and MP were detected were retested with SYBR Green-based RT-qPCRs targeting each of the MP and NP genes (primers described in Supplementary Table S1). MP was unequivocally detected in all samples, with melting curve analysis of reactions producing a clear single dissociation curve. In contrast, NP detection often corresponded in two peaks in the dissociation curve (Table 2 ), and an absence of a clear PCR product into these qPCR reactions was confirmed after gel electrophoresis. Thus, as the MP region produced overall more consistent results in CiVA detection than the NP, the respective quantitative RT-qPCR was selected for further evaluation and compared with the conventional RT-PCR targeting the MP gene.

Sensitivity of the RT-(q)PCR assays was examined by estimating the detection limit for the MP gene target by using serially diluted transcript standards and RNA from a CiVA-infected citrus tree, into CiVA-negative sweet orange RNA.

When 10-fold serial dilutions of RNA standards were used, detection endpoints were $10^{2}$ copies for both the quantitative and
A

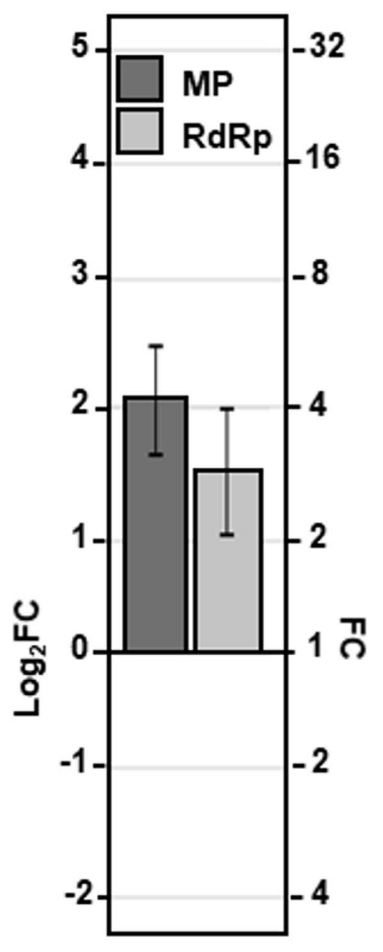

\section{B}

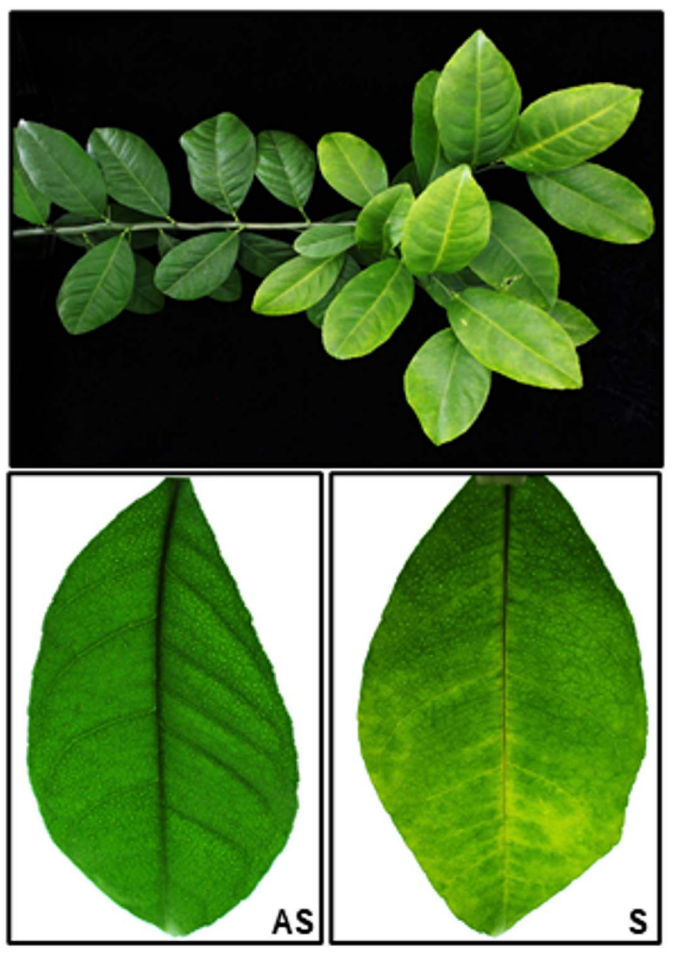

C

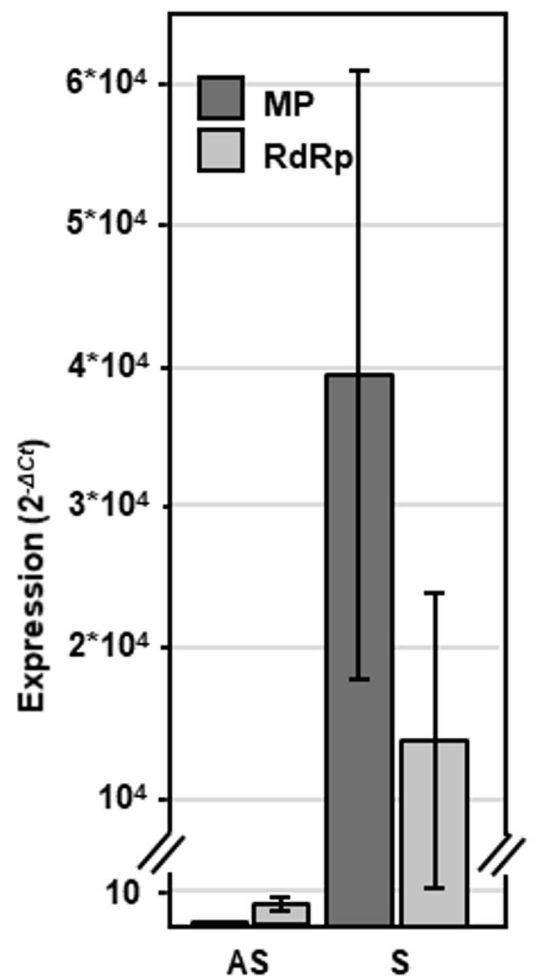

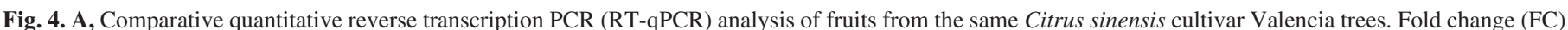

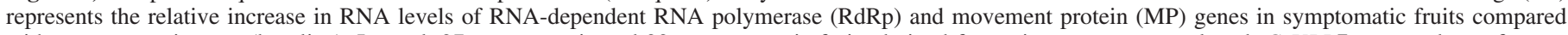

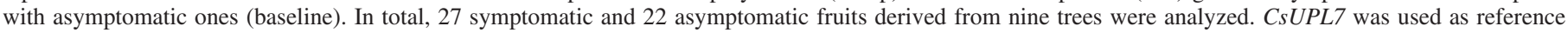

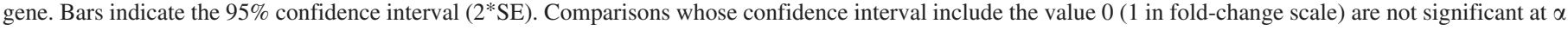

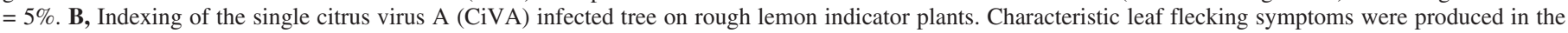

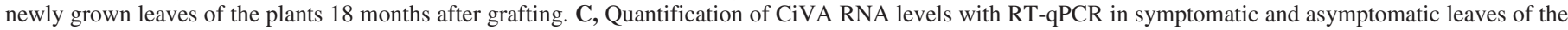

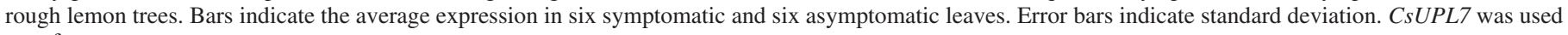
as reference gene. 
conventional RT-PCR assays. In conventional RT-PCR a faint band was observed in the sample containing $10^{2}$ copies, whereas in RT-qPCR the dissociation curve revealed the presence of a second lower nonspecific peak (Fig. 5). The RT-qPCR assay on serially diluted RNA from the naturally infected plant in sweet orange RNA detected the virus up to a $10^{-5}$ dilution, whereas conventional RT-PCR detected up to a $10^{-4}$ dilution (Fig. 5). The detection efficiency of the quantitative assay with standards was $98.7 \%$, with regression coefficient values $\left(R^{2}\right)$ of 0.998 . Efficiency and $R^{2}$ values using RNA extracted from the naturally infected tree were $101.94 \%$ and 0.994 , respectively. The constructed standard curves are presented in Figure 5.

TABLE 2. Comparison between the developed conventional reverse transcription PCR (RT-PCR) and SYBR Green-based quantitative RT-PCR (RT-qPCR) methods targeting each of the nucleocapsid protein (NP), the movement protein (MP), and the RNA-dependent RNA polymerase (RdRp) genomic regions of citrus virus $\mathrm{A}$, in asymptomatic fruits originating from the same tree ${ }^{\mathrm{a}}$

\begin{tabular}{|c|c|c|c|c|c|c|c|}
\hline \multirow[b]{2}{*}{ Tree } & \multirow[b]{2}{*}{ Asymptomatic } & \multicolumn{3}{|c|}{ RT-PCR } & \multicolumn{3}{|c|}{ RT-qPCR } \\
\hline & & NP & MP & $\mathrm{RdRp}$ & NP & MP & $\mathrm{RdRp}$ \\
\hline \multirow[t]{3}{*}{ A1 } & AS1 & + & + & + & $\mathrm{MuPk}$ & + & + \\
\hline & AS2 & + & + & + & $\mathrm{MuPk}$ & + & + \\
\hline & AS3 & - & + & + & + & + & + \\
\hline \multirow[t]{3}{*}{$\mathrm{A} 2$} & AS1 & - & + & + & $\mathrm{MuPk}$ & + & + \\
\hline & $\mathrm{AS} 2$ & + & + & + & $\mathrm{MuPk}$ & + & + \\
\hline & AS3 & + & + & + & MuPk & + & + \\
\hline \multirow[t]{2}{*}{ A3 } & AS1 (BAs) ${ }^{b}$ & - & + & + & MuPk & + & + \\
\hline & AS2 & + & + & + & MuPk & + & + \\
\hline \multirow[t]{3}{*}{ A4 } & AS1 & + & + & + & $\mathrm{MuPk}$ & + & + \\
\hline & AS2 & - & + & + & + & + & + \\
\hline & AS3 & - & + & + & MuPk & + & + \\
\hline \multirow[t]{2}{*}{ A5 } & AS1 & + & + & + & $\mathrm{MuPk}$ & + & + \\
\hline & AS2 & - & + & + & + & + & + \\
\hline \multirow[t]{2}{*}{ A6 } & AS1 & - & + & + & + & + & + \\
\hline & $\mathrm{AS} 2$ & + & + & + & $\mathrm{MuPk}$ & + & + \\
\hline \multirow[t]{3}{*}{ A7 } & AS1 & - & + & + & + & + & + \\
\hline & AS2 & - & + & + & + & + & + \\
\hline & AS3 & + & + & + & MuPk & + & + \\
\hline \multirow[t]{2}{*}{ A8 } & AS1 & + & + & + & $\mathrm{MuPk}$ & + & + \\
\hline & AS2 & - & + & + & + & + & + \\
\hline \multirow[t]{2}{*}{ A9 } & AS1 & - & + & + & + & + & + \\
\hline & AS2 & + & + & + & MuPk & + & + \\
\hline
\end{tabular}

a The same complementary DNA template was used in all methods tested. Samples detected positive are indicated by (+) and negative samples by (-). $M u P k$ refers to samples that showed multiple peaks to the dissociation curve analysis in the RT-qPCR assays and thus could not be characterized as positives or negatives.

b BAs, asymptomatic fruit sample analyzed with high-throughput sequencing.

TABLE 3. Validation of the SYBR Green-based quantitative reverse transcription PCR (RT-qPCR) targeting the MP of citrus virus A in asymptomatic citrus species and comparison with conventional RT-PCR targeting the nucleocapsid (NP) and movement protein (MP)

\begin{tabular}{lcccc}
\hline & & \multicolumn{3}{c}{ No. of positives/method } \\
\cline { 3 - 4 } & $\begin{array}{c}\text { No. trees } \\
\text { tested }\end{array}$ & NP & MP & RT-qPCR \\
\cline { 3 - 5 } \cline { 3 - 4 } Species & 2 & 1 & 1 & MP \\
\hline Bergamot & 1 & 0 & 0 & 1 \\
Citron & 9 & 0 & 0 & 0 \\
Grapefruit & 4 & 2 & 2 & 0 \\
Lemon & 1 & 0 & 0 & 2 \\
Lime & 26 & 1 & 4 & 0 \\
Mandarin & 1 & 0 & 0 & 4 \\
Pomelo & 1 & 0 & 0 & 0 \\
Sanguine orange & 1 & 0 & 0 & 0 \\
Sour orange & 41 & 4 & 6 & 6 \\
Sweet orange & 87 & 7 & 12 & 12 \\
Total & & & & 0 \\
\hline
\end{tabular}

Finally, a total of 86 samples, derived from nurseries and fields around Greece, which included several citrus species, were tested by both conventional RT-PCR and the newly developed RT-qPCR. No difference was recorded between the conventional RT-PCR and the SYBR Green-based RT-qPCR in the number of positive samples (Table 3). CiVA was detected in 12 of 86 samples corresponding to six sweet oranges, four mandarins, one lemon, and one bergamot sample derived from almost all regions tested. The specificity of the two methods was verified with samples infected with common nontarget citrus-infecting viruses (CPsV, CTV, and CVV) and viroids (HSVd, CEVd, CBCVd, and CDVd) as well as CiVA-free citrus species (sweet orange, Mexican lime, rough lemon, sweet tangor, and sour orange).

\section{DISCUSSION}

Although CID was originally described in 1930, its causal agent remained unknown. In this study, HTS was used to identify the infectious agent associated with the disease. The analysis revealed the presence of common citrus-infecting viroids and the recently described CiVA in symptomatic samples. The virus belongs to the novel Coguvirus genus of the Bunyavirales order and has a bipartite genome consisting of a negative strand RNA, encoding the RdRp, and an ambisense RNA that produces the nucleocapsid (NP) and movement (MP) proteins (Navarro et al. 2018b). This is the first report of CiVA detection in Greece. The two Greek CiVA isolates analyzed contain the characteristic Bunya-RdRp and Tenui- $\mathrm{N}$ conserved domains and showed $96 \%$ nucleotide identity with each other. CiVA was originally described in a nonsymptomatic orange leaf sample, and it was not linked to any symptoms (Navarro et al. 2018b). Recent studies showed that the virus was detected in old citrus collections in samples showing "psorosis-like" disease symptoms, and it could induce leaf flecking and oak leaf patterns in indicator plants (Bester et al. 2021). However, the authors concluded that further studies are needed before a clear association of CiVA with these "psorosis-like" disease symptoms is proposed. In the present study CiVA was ubiquitously detected in all CID symptomatic trees and not in neighboring trees of the same age without a record of CID symptoms. Importantly, in a CID symptomatic tree CiVA was the only viral pathogen detected. In addition, indexing through grafting of the single infected CiVA tree in rough lemon indicator plants resulted in the appearance of characteristic leaf flecking symptoms (Bar-joseph and Loebenstein 1970; Caruso et al. 1993) that were also correlated with the titer of the virus. These observations strongly supported the hypothesis that CiVA is the causal agent of CID.

To investigate the sporadic appearance of CID symptomatic fruits in a single tree, the distribution of CiVA was examined through RT-qPCRs targeting the two genomic segments of the virus (RdRP and MP). The comparative analysis among symptomatic and asymptomatic fruits derived from the same trees showed a statistically significant reduction of CiVA accumulation in fruits without CID symptoms. These results indicated that the appearance of symptoms occurred when the concentration of the virus in this tissue exceeded a certain amount. An uneven distribution of viruses during systemic infection is not uncommon in both herbaceous (Asano et al. 2017; Green et al. 1988) and perennial plant species (Galipienso et al. 2004; Kominek et al. 2009; Rodio et al. 2006). However, reports of a link between the appearance of symptoms and virus concentration are scarce (Noda et al. 2017). In perennial crops, it was shown that the development of mosaic symptoms in apple trees was correlated with the differential quantity of apple necrotic mosaic virus in the different leaves (Noda et al. 2017). It is well established that viral populations could differentiate and evolve independently within a single perennial host over a long period of time. Specifically for plum pox virus, it was shown that after systemic invasion of one Prunus tree, the virus population differentiated into several distinct populations that were isolated in the different branches, in which they evolved 
independently (Jridi et al. 2006). Along these lines, the analysis of CiVA population in symptomatic and asymptomatic orange fruits revealed the presence of diverse SNVs in terms of quantity, quality, and distribution along the $\mathrm{L}$ and $\mathrm{M}$ sequences. In addition, a single nucleotide substitution in the intergenic region of the ambisense $\mathrm{M}$ RNA of CiVA in the asymptomatic fruits was identified, which could lead to the impairment of the TTS in the viral RNA strand. Thus, it is plausible that a reduced production of the NP messenger RNAs occurs in the asymptomatic branches. In line with this hypothesis, in the phylogenetically related Phlebovirus genus it was shown that the two TTS sites in the ambisense RNA segment act independently, and a mutation in one TTS site resulted in absence of messenger RNA and thus in the corresponding protein but not in the genomic viral and viral complementary strands (Albariño et al. 2007). Therefore, the differential appearance of CID symptoms among the branches of a given tree might be attributed not only to virus quantity but also to differences in virus population genetic structure. However, extensive genetic population studies are needed to elucidate the pathogenicity of specific viral haplotypes and how they interact with the host before safe conclusions can be drawn.

According to the European legislation the CID causal agent is a regulated nonquarantine pest, and thus it should be absent from certified propagation material. In this context a fast and reliable method for the detection of CID is needed. Our results suggest that CiVA is clearly associated with the disease, and therefore the RT-(q)PCR assays used to characterize the virus were further evaluated as a detection tool. In general, the NP gene of a virus is usually considered an appropriate target for its detection because of its high expression. Recently a multiplex RT-PCR protocol was proposed for the simultaneous detection of $\mathrm{CiVA}$ and $\mathrm{CCGaV}$ targeting the NP gene of the two viruses (Minutolo et al. 2020). However, in the present study the NP targeting RT-(q)PCRs produced a number of false negative results. This could be attributed to the uneven distribution and low concentration of the virus or to highly variable NP sequences in virus population among the different trees. The latter was observed in two closely related to CiVA viruses, apple rubbery wood 1 and 2. As shown by Rott et al. (2018), a single primer pair targeting the NP was unable to detect all infected trees because of the highly divergent NP sequences, whereas primers amplifying a part of the RdRp of the viruses were the most reliable. In the present study, the RT-(q)PCRs targeting the MP gene produced identical results to the assays targeting the RdRp of CiVA. In addition, the RdRp of negative strand RNA viruses is expressed at lower levels compared with the rest of virus genes and constitutes generally a more difficult target for PCR amplification (Kormelink et al. 2011). Considering these points, the RT-qPCR that targets the movement protein of CiVA was chosen for further evaluation as a detection method, and it was compared with the respective conventional RT-PCR. The two assays displayed similar specificity, with the quantitative RT-qPCR being more sensitive by a factor of 10 . Amplification efficiencies of $100 \%$ and regression coefficient values $\left(R^{2}\right)>0.99$ were obtained, demonstrating accuracy and linear response of the assay over a wide range of dilutions. These performance criteria further verified the suitability of the developed assay to detect and quantify the virus in plant material. In addition, the small-scale survey conducted during validation of the methods revealed the presence of the virus in $14 \%$ of the asymptomatic trees tested from several citrus-cultivating regions of Greece.
A

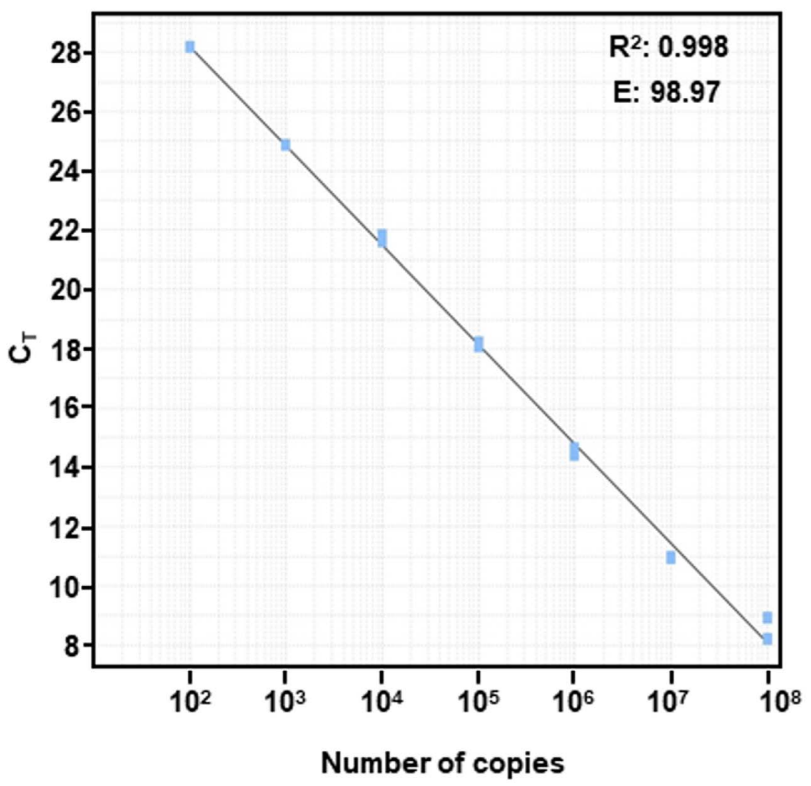

C

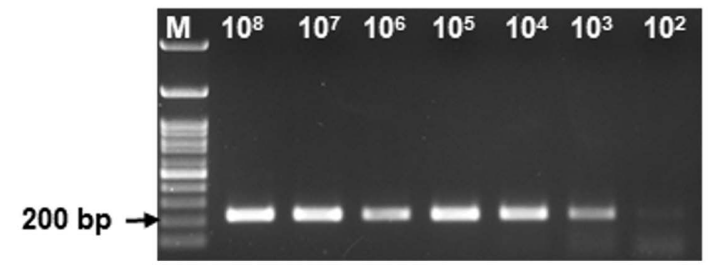

B

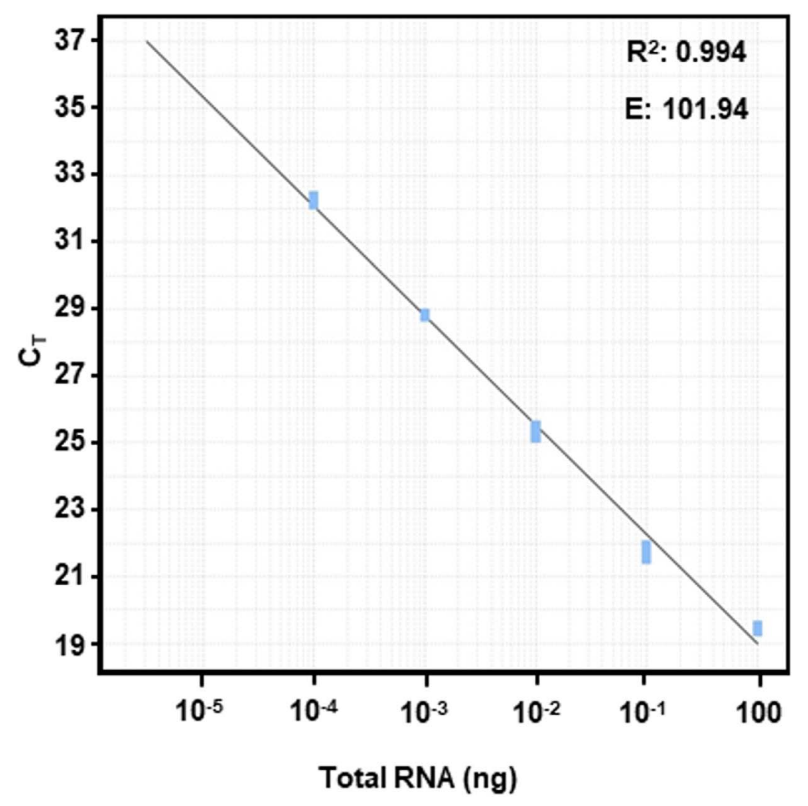

D

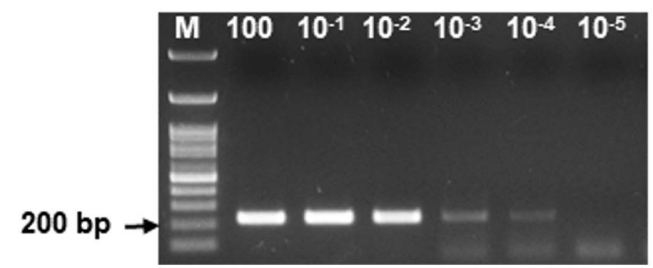

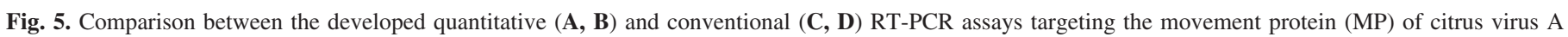

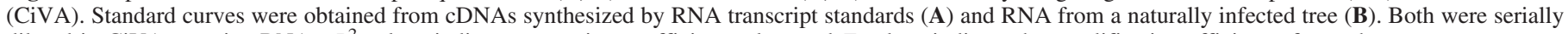
diluted in CiVA-negative RNAs. $R^{2}$ values indicate regression coefficient value, and $E$ values indicate the amplification efficiency for each case. 
In summary, beside the first detection of CiVA in Greece, we report strong evidence of a causal association of CiVA with CID. To date, numerous publications have reported the use of HTS technologies to detect new or poorly characterized plant viruses in fruit trees, but only few of them further investigated the association of the identified viruses with disease symptoms (Hou et al. 2020). In the present work, this association was supported by the sole presence of CiVA in a CID symptomatic tree, the link between symptom appearance and virus RNA accumulation, and the positive indexing on rough lemon indicator plants. In addition, two detection methods were developed and evaluated for the reliable detection of the virus in citrus species that could be used during certification programs of Citrus spp. propagation material.

\section{ACKNOWLEDGMENTS}

We thank Konstantina Spanou and Maria Marathianou for their technical assistance in the survey and symptom monitoring of impietratura trees in the Argolida orchard and H. J. Maree for providing positive controls and methods for citrus virus screening.

\section{LITERATURE CITED}

Albariño, C. G., Bird, B. H., and Nichol, S. T. 2007. A shared transcription termination signal on negative and ambisense RNA genome segments of Rift Valley fever, sandfly fever Sicilian, and Toscana viruses. J. Virol. 81: 5246-5256.

Asano, S., Hirayama, Y., and Matsushita, Y. 2017. Distribution of Tomato spotted wilt virus in dahlia plants. Lett. Appl. Microbiol. 64:297-303.

Bar-joseph, M., and Loebenstein, G. 1970. Leaf flecking on indicator seedlings, associated with citrus impietratura in Israel: a possible indexing method. Plant Dis. Rep. 54:643-645.

Bester, R., Karaan, M., Cook, G., and Maree, H. J. 2021. First report of citrus virus A in citrus in South Africa. J. Citrus Pathol. 8. https://escholarship.org/ uc/item/5gr6p8zh.

Caruso, A., Davino, G. C., and Terranova, G. 1993. Observations on impietratura disease symptoms in four citrus species. International Organization of Citrus Virologists Conference Proceedings (1957-2010) 12:379-382.

Cook, G., van Vuuren, S. P., Breytenbach, J. H. J., and Manicom, B. Q. 2012. Citrus viroid IV detected in Citrus sinensis and C. reticulata in South Africa. Plant Dis. 96:772.

Diaz-Lara, A., Navarro, B., Di Serio, F., Stevens, K., Hwang, M. S., Kohl, J., et al. 2019. Two novel negative-sense RNA viruses infecting grapevine are members of a newly proposed genus within the family Phenuiviridae. Viruses 11:685.

Fox, A. 2020. Reconsidering causal association in plant virology. Plant Pathol. 69:956-961.

Galipienso, L., Carmen Vives, M., Navarro, L., Moreno, P., and Guerri, J. 2004. Detection of Citrus leaf blotch virus using digoxigenin-labeled cDNA probes and RT-PCR. Eur. J. Plant Pathol. 110:175-181.

Garrison, E., and Marth, G. 2012. Haplotype-based variant detection from short-read sequencing. arXiv 1207.3907.

Green, S. K., Kuo, Y. J., and Lee, D. R. 1988. Uneven distribution of two potyviruses (feathery mottle virus and sweet potato latent virus) in sweet potato plants and its implication on virus indexing of meristem derived plants. Trop. Pest Manage. 34:298-302.

Hou, W., Li, S., and Massart, S. 2020. Is there a "biological desert" with the discovery of new plant viruses? A retrospective analysis for new fruit tree viruses. Front. Microbiol. 11:592816. https://www.frontiersin.org/articles/ 10.3389/fmicb.2020.592816/full.

Ito, T., Ieki, H., and Ozaki, K. 2002. Simultaneous detection of six citrus viroids and Apple stem grooving virus from citrus plants by multiplex reverse transcription polymerase chain reaction. J. Virol. Methods 106: 235-239.

Jridi, C., Martin, J.-F., Marie-Jeanne, V., Labonne, G., and Blanc, S. 2006. Distinct viral populations differentiate and evolve independently in a single perennial host plant. JVI 80:2349-2357.

Kominek, P., Glasa, M., and Kominkova, M. 2009. Analysis of multiple virusinfected grapevine plant reveals persistence but uneven virus distribution. Acta Virol. 53:281-285.
Kormelink, R., Garcia, M. L., Goodin, M., Sasaya, T., and Haenni, A.-L. 2011. Negative-strand RNA viruses: the plant-infecting counterparts. Virus Res. 162:184-202.

Mafra, V., Kubo, K. S., Alves-Ferreira, M., Ribeiro-Alves, M., Stuart, R. M., Boava, L. P., et al. 2012. Reference genes for accurate transcript normalization in citrus genotypes under different experimental conditions. PLoS One 7:e31263.

Malandraki, I., Beris, D., Isaioglou, I., Olmos, A., Varveri, C., and Vassilakos, N. 2017. Simultaneous detection of three pome fruit tree viruses by one-step multiplex quantitative RT-PCR. PLoS One 12:e0180877.

Massart, S., Candresse, T., Gil, J., Lacomme, C., Predajna, L., Ravnikar, M., et al. 2017. A framework for the evaluation of biosecurity, commercial, regulatory, and scientific impacts of plant viruses and viroids identified by NGS Technologies. Front. Microbiol. 8:45.

Minutolo, M., Di Serio, F., Cinque, M., Lombardi, P., Navarro, B., and Alioto, D. 2020. Simultaneous detection of citrus concave gum-associated virus $(\mathrm{CCGaV})$ and citrus virus A (CiVA) by multiplex RT-PCR. J. Plant Pathol. 102:655-661.

Navarro, B., Minutolo, M., Stradis, A. D., Palmisano, F., Alioto, D., and Serio, F. D. 2018a. The first phlebo-like virus infecting plants: A case study on the adaptation of negative-stranded RNA viruses to new hosts. Mol. Plant Pathol. 19:1075-1089.

Navarro, B., Zicca, S., Minutolo, M., Saponari, M., Alioto, D., and Di Serio, F. 2018b. A negative-stranded RNA virus infecting citrus trees: the second member of a new genus within the order Bunyavirales. Front. Microbiol. 9:2340.

Noda, H., Yamagishi, N., Yaegashi, H., Xing, F., Xie, J., Li, S., et al. 2017. Apple necrotic mosaic virus, a novel ilarvirus from mosaic-diseased apple trees in Japan and China. J. Gen. Plant Pathol. 83:83-90.

Osman, F., Hodzic, E., Kwon, S.-J., Wang, J., and Vidalakis, G. 2015. Development and validation of a multiplex reverse transcription quantitative PCR (RT-qPCR) assay for the rapid detection of Citrus tristeza virus, Citrus psorosis virus, and Citrus leaf blotch virus. J. Virol. Methods 220:64-75.

Rodio, M.-E., Delgado, S., Flores, R., and Serio, F. D. 2006. Variants of Peach latent mosaic viroid inducing peach calico: Uneven distribution in infected plants and requirements of the insertion containing the pathogenicity determinant. J. Gen. Virol. 87:231-240.

Roistacher, C. N. 2004. Diagnosis and management of virus and virus like diseases of citrus. Pages 109-189 in Diseases of Fruits and Vegetables Volume I: Diagnosis and Management, S. A. M. H. Naqvi, ed. Springer, Dordrecht, the Netherlands.

Rott, M. E., Kesanakurti, P., Berwarth, C., Rast, H., Boyes, I., Phelan, J., and Jelkmann, W. 2018. Discovery of negative-sense RNA viruses in trees infected with Apple rubbery wood disease by next-generation sequencing. Plant Dis. 102:1254-1263.

Roy, A., Fayad, A., Barthe, G., and Brlansky, R. H. 2005. A multiplex polymerase chain reaction method for reliable, sensitive and simultaneous detection of multiple viruses in citrus trees. J. Virol. Methods 129:47-55.

Ruijter, J. M., Ruiz Villalba, A., Hellemans, J., Untergasser, A., and van den Hoff, M. J. B. 2015. Removal of between-run variation in a multi-plate qPCR experiment. Biomol Detect. Quantif. 5:10-14.

Steibel, J. P., Poletto, R., Coussens, P. M., and Rosa, G. J. M. 2009. A powerful and flexible linear mixed model framework for the analysis of relative quantification RT-PCR data. Genomics 94:146-152.

Svanella-Dumas, L., Marais, A., Depasse, F., Faure, C., Lefebre, M., Brans, Y., et al. 2019. First report of Citrus virus A (CiVA) infecting pear (Pyrus communis) in France. Plant Dis. 103:2703.

Thompson, J. R., Wetzel, S., Klerks, M. M., Vašková, D., Schoen, C. D., Špak, J., et al. 2003. Multiplex RT-PCR detection of four aphid-borne strawberry viruses in Fragaria spp. in combination with a plant mRNA specific internal control. J. Virol. Methods 111:85-93.

Timmer, L. W., Garnsey, S. M., and Graham, J. H., eds. 2000. Compendium of Citrus Diseases, 2nd ed. American Phytopathological Society, St. Paul, MN.

Villamor, D. E. V., Ho, T., Al Rwahnih, M., Martin, R. R., and Tzanetakis, I. E. 2019. High throughput sequencing for plant virus detection and discovery. Phytopathology 109:716-725.

Wang, X., Zhou, C., Tang, K., Zhou, Y., and Li, Z. 2009. A rapid one-step multiplex RT-PCR assay for the simultaneous detection of five citrus viroids in China. Eur. J. Plant Pathol. 124:175-180.

Wright, A. A., Szostek, S. A., Beaver-Kanuya, E., and Harper, S. J. 2018. Diversity of three bunya-like viruses infecting apple. Arch. Virol. 163: 3339-3343. 